\title{
Contraceptive services: counter-reformation and population dynamics
}

\author{
Lindsay Edouard
}

International Advisory Editor Port Louis, Mauritius

Correspondence to Professor Lindsay Edouard; soranae@gmail.com

Received 26 June 2011 Accepted 29 July 2011

\section{Summary}

World population is expected to reach 7 billion within the next month. It is therefore timely to consider the relationship of contraceptive services, with their focus on the individual, to implications for population dynamics. The various facets include individual choice, human rights, health benefits, socioeconomic implications and the demographic goals of governments. These all have their own rationale, with the common approach that contraception is much needed for fertility control in society, despite certain views that might limit its availability. Many obstacles still need to be overcome for the widespread provision of contraception to become an integral part of comprehensive health services.

\section{Population growth}

Twenty-five years ago, in 1986, this Journal published a report on the XIIIth Current Fertility Control Symposium, held in London on 31 October 1985. In his opening presentation, Professor Norman Morris had addressed the issue of population control. ${ }^{1}$ It was then anticipated that the world population would reach 5 billion on 11 July 1987, 13 years after the milestone of 4 billion in 1974 . Morris pointed out the disparity between zero population growth in Europe and the "alarming" high fertility in developing countries, associated with their youth bulge. He alluded to the relationship to global food needs before specifying the roles of literacy, late marriage, strong family planning programmes and "a more equitable distribution of income and services and a world-wide effort to raise the status of women". ${ }^{1}$ Thus, a clinical meeting in London already had perspectives that, 15 years later, were at centre stage for the calls for poverty reduction and gender equity that were to be among the Millennium Development Goals in 2000.
In 1986, population growth had long been perceived as leading to a strain on world resources. But the contribution of modern methods of contraception to population control was recognised to be inadequate due to their low utilisation and it was felt that there should be "better marketing of contraception and the development of culturally acceptable methods". ${ }^{2}$

\section{Integrated services}

In Britain, the concept of integrated services was gaining increasing support following consideration of alternative models for training and service delivery. Writing in this Journal, Dame Josephine Barnes specified the importance of the women's movement in promoting "better services for women at all times in their lives" and not merely for childbirth. ${ }^{3}$ This approach was exemplified by the interface between hospital gynaecology and contraceptive services: David Horwell emphasised the need for the continuation of the woman's current effective contraceptive method following the diagnosis of cervical intraepithelial neoplasia, but also reflected the view that barrier contraception might play a part in the prevention of cervical cancer in view of the recognition of the probable involvement of wart viruses in its aetiology. ${ }^{4}$ Sexual health was seen as an important aspect of the provision of family planning services ${ }^{5}$ and especially as a component of primary health care. ${ }^{6}$

\section{Youth}

Services for youth were a major preoccupation whether for the individual, family, community or country. Regarding services to minors, in March 1986 the government issued revised guidelines for family planning services for young people that complemented the statement by the General Medical Council regarding the course of action to be taken when "the young girl is not mature enough to understand what is involved in the treatment": confidentiality 
of the consultation could be waived exceptionally to permit parental involvement. ${ }^{7}$ It was felt that the unmet contraceptive needs of teenagers were so important as to justify the intervention of general practitioners by their raising the issue spontaneously during any medical consultation. ${ }^{8}$

\section{Counter-reformation}

In his 1986 George Morris Memorial Lecture, Malcolm Potts viewed the late 1960s as the reformation period for family planning, with its final acceptance in the international development movement. The 1970s then represented a golden decade when family planning was recognised for its potential to solve the problems of population growth and food shortage, thereby contributing towards socioeconomic development. ${ }^{9}$

However, Potts considered that in the 1980s there had been a counter-reformation movement leading to damage to progress on several fronts, with views that "perceptions of morality are more important than the reality of particular family planning technologies". With their safety being questioned, intrauterine devices and injectables were removed from the range of available contraceptive methods in the USA, where the Reagan administration also introduced restrictions in the availability of reproductive health services. Potts felt that the counter-reformation movement had interpreted "the availability of contraception to the unmarried as a Pied Piper which has drawn the young into a black cave of hedonism". As examples of the strong influences of religion and politics, Potts deplored the lack of services for voluntary sterilisation in Egypt and the maintenance of French colonial laws prohibiting contraception on the statute books in sub-Saharan Africa. Potts was remarkably percipient in pointing out at that time, 1986, that "Egyptian social life collapses under the frustrations of unemployed millions of youth". ${ }^{9}$

\section{The milestone of 7 billion}

The United Nations has proclaimed 31 October 2011 as the day when the world population will reach 7 billion, the last milestone of 6 billion having been reached in 1999 and the next one of 8 billion being expected in 2025. With the anticipated discussions on the time lag for replacement fertility level and a possible plateau of world population, it is imperative that long-term population projections are perceived as being a range of possibilities with numerous potential variants. These estimations do not benefit from crystal ball gazing and consideration must be given to the effects of changes in population policies, political turbulence and, most importantly, limited financial and human resources that are insufficient to meet the demand for contraceptive services. There are vast differences between regions and countries regarding both population policies and demographic indicators, but it should be acknowledged that the least developed countries usually view their fertility as being too high. Continuing support is therefore essential for the strengthening of family programmes through both advocacy and service delivery, as part of comprehensive reproductive health services. ${ }^{10}$

Major demographic issues do not relate to mere numbers but rather to the youth bulge and ageing with their resulting socioeconomic effects and the dependency ratio that compares working to non-working populations. In some countries in transition, educated young women face high unemployment rates as they are overqualified for the existing job market. Rapid modernisation, development and globalisation lead to sophisticated youth. Women now have drastically different expectations from those of earlier generations, such issues being more significant in traditional societies. Instead of applying earlier models from other countries, ${ }^{11}$ culturally sensitive solutions must be sought with the participation of women and youth in policy formulation.

Since January 2011, movements in various countries such as Egypt and Tunisia have demonstrated the role of women and youth in uprisings that seek social change. By coincidence, UN Women became operational on 1 January 2011 and the International Year of Youth, which was first proposed by Tunisia, commenced in August 2010. As far back as 2008, the National Intelligence Council of the USA had identified unmet socioeconomic needs and the ignored political rights of youth as security risks in a demographic crescent, an "arc of instability" comprised of countries with a growing population and conflict stretching from Latin America through Africa and the Middle East to Asia. ${ }^{12}$

The International Conference on Population and Development held in Cairo in 1994 led to a move from demographic goals towards individual needs, and its Programme of Action specified that targets and quotas should not be imposed on providers of family planning services. Irrespective of the demographic policies of governments, individuals should have access to contraceptive services that do not interfere with their rights regarding reproductive choice.

\section{Provision of contraceptive services}

With recent political changes in some countries, women's health services may unfortunately face restrictive legislation including limited public funding for sensitive areas such as adolescent sexual services and abortions. It is even more worrying that there is a threat to curtail access to contraceptive services through judicial decisions defining when life begins. The issue of whether life commences when sperm meets egg or after implantation of the fertilised ovum in the uterus is actually in the theological domain. But it has lately been difficult for law, religion, politics and policymaking to keep up with scientific advances in the physiology of reproductive health. With less than half of all 
fertilised ova proceeding beyond implantation in the natural state, it would be extremely regrettable if intrauterine and emergency contraception, and even oral contraceptives, were regarded as being abortifacient. Should viability be recognised as occurring at fertilisation, major problems would, for example, be faced in the management of ectopic pregnancy with its lifethreatening complications.

Contraceptive services are accepted as among the most cost-effective interventions for global health. The rationale includes their benefits for women's and children's health, human rights, demography and socioeconomic development, quite apart from the neo-Malthusian ones relating to food security, the environment, ecology, global warming and pollution. Cultural considerations are important for societies to appreciate the potential of technological developments. Reproductive health professionals have a duty to contribute towards responsible policymaking through informed discussion, to ensure universal access to health services.

This approach should draw upon the bold new commitment by member countries at the United Nations in New York in June this year: in a revolutionary change, the 'vertical approach' to HIV control will be replaced by integrated global health. ${ }^{13}$ This initiative will provide the exceptional opportunity of drawing upon a comprehensive set of interventions that will incorporate the scaling up of family planning services, aiming at the elimination by 2015 of unmet need for contraception for women at risk of HIV, in order to reduce HIV-associated maternal deaths and neonatal HIV infection by $90 \%$. The timescale for this momentous achievement is just four short years. It remains to be seen whether the worthy words of the political leaders at this major forum will be translated into the huge commitments of national and international determination, finances and human resources that will be required.

Competing interests None.

Provenance and peer review Commissioned; internally peer reviewed.

\section{References}

1 Devereux B, Gregson E, Main A. XIIIth Current Fertility Control Symposium of the Department of Obstetrics and Gynaecology, Charing Cross Hospital on October 31, 1985. Br J Fam Plann 1986;11:155-156.

2 Anonymous. Contraception 1985; 32, Nos 1, 2, 3. Br J Fam Plann 1986;12:25.

3 Barnes J. Medical gynaecology. Br J Fam Plann 1986;12:1-2.

4 Nash C, Randall S. Reports - Symposium organised by the National Association of Family Planning Doctors on April 4/5 1986 at the Union Society Building, Cambridge University. Br J Fam Plann 1986;12:74-76.

5 Skrine R. Family planning: the service, the doctor and the patient. Br J Fam Plann 1986;12:23-25.

6 Tacchi D. Primary health care - an agenda for discussion. Br J Fam Plann 1986;12:81.

7 Anonymous. Minutes of AGM. Br J Fam Plann 1986;12:78-80.

8 Bury JK. Teenagers and contraception - II. Br J Fam Plann 1986;12:42-47.

9 Potts M. Dr George Morris Memorial Lecture 1986 - Counter reformation in family planning. Br J Fam Plann 1986;12:50-56.

10 Potts M, Campbell M. The myth of 9 billion. Foreign Policy, 9 May 2011.

11 Chabot HT. Primary health care will fail if we do not change our approach. Lancet 1984;2:340-341.

12 National Intelligence Council. Global Trends 2025: A Transformed World. Washington, DC: US Government Printing Office, 2008;iv,viii, 21.

13 Editorial. A strategic revolution in HIV and global health. Lancet 2011;377:2055. 